\title{
NECROPSIES IN SOME CONGENITAL DISEASES OF THE HEART, MAINLY FALLOT'S TETRALOGY
}

\author{
BY \\ W. D. BRINTON AND MAURICE CAMPBELL \\ From the Cardiac Department, Guy's Hospital \\ Received December 3, 1952
}

In spite of great progress in the clinical diagnosis of congenital heart lesions, especially with the help of cardiac catheterization and angiocardiography, these methods still fall short of complete proof and advances must be firmly based on fundamental facts of morbid anatomy. It has, therefore, been thought worth while to examine in detail the anatomy and pathology of this series of 55 necropsies made at Guy's Hospital between May, 1947, and March, 1950, on patients with congenital heart disease, especially as in most of them the history and clinical findings in life were well known.

Of the 55 cases, 25 consisted of Fallot's tetralogy and it is these that will be considered in most detail. There were 6 others with most of the features of Fallot's tetralogy but with pulmonary atresia; these have been fully reported by Allanby, et al. (1951) and reasons were given for separating them from Fallot's tetralogy because of the difference in their surgical treatment. The remaining 24 covered a wide range of developmental abnormalities (see Table II).

\section{FALLOT'S TETRALOGY}

The twenty-five patients in this group are shown in Table I. Most were between 7 and 20 years of age. The classical characteristics of the tetralogy were clearly displayed in all these and the only instances in which further diagnostic comment is needed are Case 9, in which both the atrial and ventricular septal defects were so large as to amount to a bilocular heart (Case 5, Campbell et al., 1953) but the infundibular stenosis and dextroposition of the aorta were characteristic enough to place it in this group, and Case 5, where the aorta arose entirely from the right ventricle and the ventricular septal defect was unusually small.

Emphasis was laid on displaying the abnormalities found, so when the heart was fresh the other mediastinal contents were kept attached to it and even in the final dissection the great vessels were usually left. The weight of the heart is, therefore, not always available but some idea of its size is given by the measurements of the thickness of the ventricular muscle and of the diameters of the aorta and pulmonary artery, all these measurements being made when the hearts were fresh.

Defects of the Atrial Septum. In 15 of the 25 cases there was no functional defect of the atrial septum; in many of these there was a slit- or probe-patency that was easy to distinguish from an effective patency. In the remaining 10 there was a functional defect: in Case 9 it was so large that there was hardly a septum and in Case 6 it was relatively large, but in the other nine it was not often more than 10 . by $7 \mathrm{~mm}$. or less than 6 by $3 \mathrm{~mm}$. (see Table I) and averaged 9.2 by $4.7 \mathrm{~mm}$. No correlation could be found between the presence and size of these defects and any other factor.

The Ventricular Septal Defect. This was strikingly similar in each heart, with the exception of Case 9 in which the septum was represented by a mere ridge at the bottom of an almost common ventricle, and Case 5 in which the defect was unusually small and the aorta arose entirely from the 
right ventricle. The size of the defect was, with these exceptions, highly correlated with the size of the heart, the free upper border of the septum lying beneath the valves of the dextroposed aorta in the same relationship regardless of size. The transverse diameter of the defect averaged $13.6 \mathrm{~mm}$. and was generally between 6 and $20 \mathrm{~mm}$.

TABLE I

Some Measurements of the Heart in Fallot's Tetralogy

\begin{tabular}{|c|c|c|c|c|c|c|c|c|c|c|c|c|}
\hline $\begin{array}{c}\text { Case and } \\
\text { reference } \\
\text { No. }\end{array}$ & $\begin{array}{l}\text { Sex } \\
\text { and } \\
\text { age }\end{array}$ & $\begin{array}{c}\text { Vent } \\
\text { R. } \\
(\mathrm{mm} .)\end{array}$ & $\begin{array}{l}\text { icular } \\
\text { L. } \\
\text { (mm.) }\end{array}$ & $\begin{array}{c}\text { muscle } \\
\text { ratio } \\
\mathbf{L} . / \mathbf{R} .\end{array}$ & $\begin{array}{l}\text { P.T. } \\
\text { diam. } \\
(\mathrm{mm} .)\end{array}$ & $\begin{array}{l}\text { Aorta } \\
\text { diam. } \\
(\mathrm{mm} .)\end{array}$ & P.T/A. & 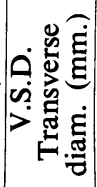 & $\begin{array}{c}\text { Site of stenosis } \\
\text { (mm. below pulm. } \\
\text { valve and type) }\end{array}$ & 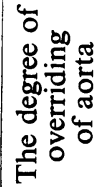 & $\begin{array}{l}\text { A.S.D. } \\
\text { diam. } \\
(\mathrm{mm} .)\end{array}$ & 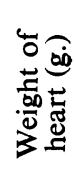 \\
\hline 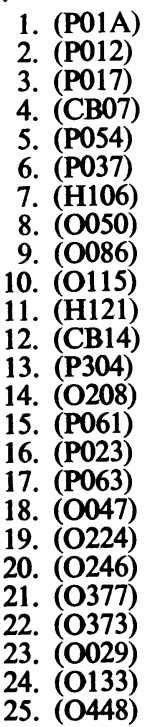 & $\begin{array}{lr}\text { M } & 19 \\
\text { F } & 11 \\
\text { F } & 7 \\
\text { F } & 9 \\
\text { M } & 11 \\
\text { F } & 7 \\
\text { F } & 7 \\
\text { M } & 4 \\
\text { M } & 18 \\
\text { M } & 27 \\
\text { F } & 24 \\
\text { F } & 12 \\
\text { F } & 6 \\
\text { F } & 14 \\
\text { F } & 36 \\
\text { M } & 7 \\
\text { M } & 29 \\
\text { F } & 5 \\
\text { F } & 20 \\
\text { F } & 20 \\
\text { M } & 17 \\
\text { F } & 7 \\
\text { M } & 11 \\
\text { M } & 8 \\
\text { M } & 12\end{array}$ & $\begin{array}{r}16 \\
11 \\
9 \\
7 \\
12 \\
14 \\
9 \\
10 \\
11 \\
17 \\
15 \\
13 \\
9 \\
9 \\
11 \\
8 \\
16 \\
8 \\
12 \\
15 \\
13 \\
10 \\
11 \\
12 \\
13\end{array}$ & $\begin{array}{r}11 \\
9 \\
8 \\
4 \\
11 \\
13 \\
7 \\
9 \\
11 \\
16 \\
14 \\
11 \\
8 \\
6 \\
8 \\
7 \\
3 \\
4 \\
10 \\
12 \\
8 \\
6 \\
9 \\
9 \\
8\end{array}$ & $\begin{array}{r}69 \\
82 \\
89 \\
57 \\
92 \\
93 \\
78 \\
90 \\
100 \\
94 \\
94 \\
85 \\
89 \\
67 \\
74 \\
88 \\
81 \\
50 \\
83 \\
80 \\
62 \\
60 \\
82 \\
75 \\
61\end{array}$ & $\begin{array}{r}10 \\
5 \\
5 \\
7 \\
13 \\
4 \\
9 \\
8 \\
20 \\
14 \\
12 \\
9 \\
8 \\
6 \\
6 \\
13 \\
9 \\
14 \\
7 \\
14 \\
10 \\
9 \\
9 \\
12 \\
15 \\
17\end{array}$ & $\begin{array}{l}15 \\
10 \\
15 \\
13 \\
15 \\
16 \\
19 \\
16 \\
21 \\
21 \\
23 \\
15 \\
13 \\
13 \\
17 \\
16 \\
21 \\
18 \\
17 \\
21 \\
23 \\
18 \\
20 \\
19 \\
19\end{array}$ & $\begin{array}{l}67 \\
50 \\
33 \\
54 \\
87 \\
25 \\
47 \\
50 \\
95 \\
67 \\
52 \\
60 \\
62 \\
46 \\
76 \\
56 \\
67 \\
39 \\
82 \\
48 \\
39 \\
50 \\
60 \\
80 \\
90\end{array}$ & $\begin{array}{r}10 \\
9 \\
11 \\
12 \\
3 \\
14 \\
7 \\
18 \\
* * \\
20 \\
16 \\
9 \\
6 \\
8 \\
14 \\
10 \\
25 \\
12 \\
18 \\
18 \\
26 \\
10 \\
10 \\
20 \\
20\end{array}$ & $\begin{aligned} & 20 \text { Long inf. } \\
& 11 \text { V.S. also } \\
& 11 \text { Long inf. } \\
& 8 \text { Long inf. } \\
& 15 \text { Inf. } \\
& 10 \text { Inf. } \dagger \\
& 6 \text { High inf. } \\
& 20 \text { Low inf. } \\
& 24 \text { Inf. } \\
& 20 \text { V.S. also } \\
& \text { V.S. only } \\
& 11 \text { Inf. } \\
& 12 \text { Inf. } \\
& 18 \text { Inf. } \\
& 18 \text { Inf. } \\
& 21 \text { Low inf. } \\
& 20 \text { Inf. } \\
& 27 \text { V.S. also } \\
& 19 \text { Inf. } \\
& 1 \text { High Inf. } \\
& \text { V.S. only\$s } \\
& 8 \text { V.S. also } \\
& 10 \text { V.S. also } \\
& 24 \text { Multiple inf. } \\
& 19 \text { Inf. }\end{aligned}$ & $\begin{array}{l}\text { 二 } \\
\bar{Z} \\
* \\
\overline{\frac{1}{2}} \\
\frac{1}{2} \\
\frac{1}{2} \\
\frac{1}{2} \\
\frac{7}{1} \\
\frac{1}{2} \\
\frac{1}{3} \\
\frac{3}{3} \\
\frac{3}{4} \\
\frac{2}{3} \\
\frac{7}{8} \\
\frac{1}{2} \\
\frac{1}{2}\end{array}$ & $\begin{array}{c}\text { Nil } \\
\text { Nil } \\
\text { Nil } \\
\text { Nil } \\
\text { Nil } \\
14 \times 9 \dagger \\
7 \times 3 \\
4 \times 7 \\
* * \\
\text { Nil } \\
\text { Nil } \\
6 \times 3 \\
16 \times 4 \\
\text { Nil } \\
\text { Nil } \\
\text { Nil } \\
\text { Nil } \\
4 \times 2 \\
9 \times 3 \\
10 \times 4 \\
\text { Nil } \\
10 \times 10 \\
\text { Nil } \\
\text { Nil } \\
\text { Nil }\end{array}$ & 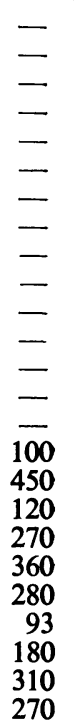 \\
\hline
\end{tabular}

* Aorta arose entirely from R.V.: very small V.S.D. (Case 5).

$\dagger$ The heart was much larger than usual, and relatively the A.S.D. was the largest except for Case 9 (Case 6). ** The atrial and ventricular septa were almost absent, and functionally there was a single ventricle (Case 9).

$\$ \S$ Died with bacterial endocarditis (Case 21).

Further, the appearance of the defect was similar in every case-a saddle-shaped ridge of muscle clothed with smooth and glistening endocardium that was not thickened or calcified, even in the older hearts in which these changes had occurred in the infundibulum to a greater or less extent. There were no vegetations attached to the defect in any case. This was particularly notable in Case 21 who was admitted with bacterial endocarditis and aortic incompetence superimposed on Fallot's tetralogy. Post mortem, a large tough vegetation, $25 \mathrm{~mm}$. long and consisting of organized thrombus, was found attached to the ventricular surface of the anterior aortic cusp and extending well into the right ventricle: it must have caused great frictional trauma to the free upper edge of the ventricular septum, but the vegetations had nowhere seeded upon it and its endocardium was normal.

The Dextroposition of the Aorta. It is difficult to measure this precisely but, in all the later hearts and in some of the earlier ones an attempt was made when the hearts were fresh; it was based on the ease with which the aortic valve could be seen from the right and left ventricles respectively, checked by observation of the free edge of the ventricular septum seen from the aorta. This estimate is 
expressed as a fraction-the degree to which the aortic ring over-rides the ventricular septal defect and thus lies over the right ventricle.

As in the other series, the degree of over-riding was very variable, the fraction expressed in this way being from one-quarter to seven-eighths, excluding Case 5, where it arose entirely from the right ventricle. It averaged three-fifths, or 60 per cent, showing that as a rule the aorta was rather more over the right than over the left ventricle. It was not possible to correlate this with any other anatomical factor in these hearts, but it is probably related to the degree of anoxæmia and cyanosis shown by the patient. Thus Cases 15 and 17, where the degree of over-riding was least, were 36 and 29 years old and had not been very cyanosed until the last years of their lives. Cases 21 and 25 , however, where the aorta seemed to be mainly from the right ventricle were not more deeply cyanosed than some others.

Right Ventricular Hypertrophy. This has been recorded as the L.V./R.V. ratio, the thickness of the left ventricle as a percentage of the thickness of the right ventricle. The ventricular muscle was measured at a point mid-way between the apex of that ventricle and the tricuspid or mitral valve.

The average L.V./R.V. ratio was two-thirds. In other words, the thickness of the right ventricle was 50 per cent greater than the left instead of being much less. It averaged $11.6 \mathrm{~mm}$. and was generally between 9 and $16 \mathrm{~mm}$., while the average for the left ventricle was $7 \cdot 8$, with most between 6 and $12 \mathrm{~mm}$.

Pulmonary Stenosis. The degree of stenosis (whether infundibular or valvular) can be expressed as the P.T./A ratio, the calibre of the pulmonary trunk as a percentage of that of the aorta. They were measured at a point $10 \mathrm{~mm}$. above the aortic or pulmonary valves, except in the smaller hearts where a level somewhat nearer the valves was chosen. This method will, of course, over-estimate the size of the pulmonary trunk when the dilatation distal to a stenosis extends so far, but this was unusual.

The diameter of the pulmonary trunk averaged $10.4 \mathrm{~mm}$. and was generally between 5 and $15 \mathrm{~mm}$. The diameter of the aorta averaged $17 \cdot 1 \mathrm{~mm}$. and was generally between 13 and $21 \mathrm{~mm}$. This gives a P.T./A ratio of 61 per cent and it was generally between 40 and 80 per cent instead of being the same size or a little larger.

The Site of the Stenosis. The outflow tract or infundibulum of the right ventricle presents the most variable and therefore the most interesting feature in these hearts, and though the series is small it contains most of the common variants. In the 25 cases, the stenosis was infundibular alone in 18, valvular alone in 2, and combined infundibular with valvular in 5: these figures are not representative (see later) probably because infundibular stenosis, provided the chamber is not too large, gives a picture that was more readily recognized as Fallot's tetralogy in 1947-48.

Infundibular Stenosis. The level of the infundibular stenosis can be high, intermediate, low, or multiple. It was generally between 5 and $24 \mathrm{~mm}$. below the valve and on the average was $15 \mathrm{~mm}$. below. A high infundibular stenosis could open from the sinus of the right ventricle immediately below the pulmonary valve, and an example of this is shown in Fig. 1. The infundibular portion of the right ventricle is then present as a chamber that extends downwards and superficially within the ventricular wall and terminates blindly at its lower end. Occasionally, with a high infundibular stenosis the infundibular cul-de-sac exists only as a potential space with the two endocardial surfaces closely apposed; more usually, however, it is a real chamber and is found to contain blood post mortem, although during life there was no current of blood through it.

At the other extreme those showing a low infundibular stenosis presented an orifice of greater or less calibre between the right ventricle and the outflow tract leading to the pulmonary valve on the left and anteriorly (Fig. 2 and 3). The outflow tract was often expanded above the stenosis, thus forming an infundibular chamber. In the older patients this was lined with endocardium that was commonly thickened, fibrous, or even calcified. Less commonly the infundibular chamber was long and narrow, though the stenosis remained low.

Between these extremes, the infundibular stenosis was found at various levels. The only striking example where it was multiple (Case 24) is described in some detail, for the tortuous passage 


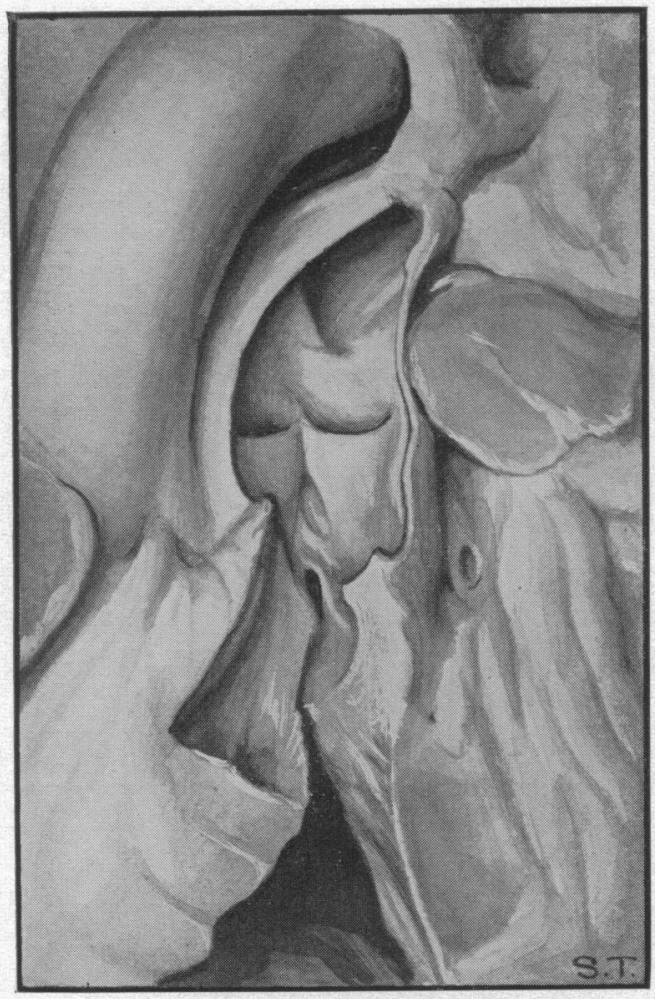

FIG. 1.-Drawing of a high infundibular stenosis. The pulmonary valve is normal, and almost immediately below it there is a fibrous infundibular stenosis without any infundibular chamber. The subclavian-pulmonary anastomosis is seen at the top of the figure. Case 20.

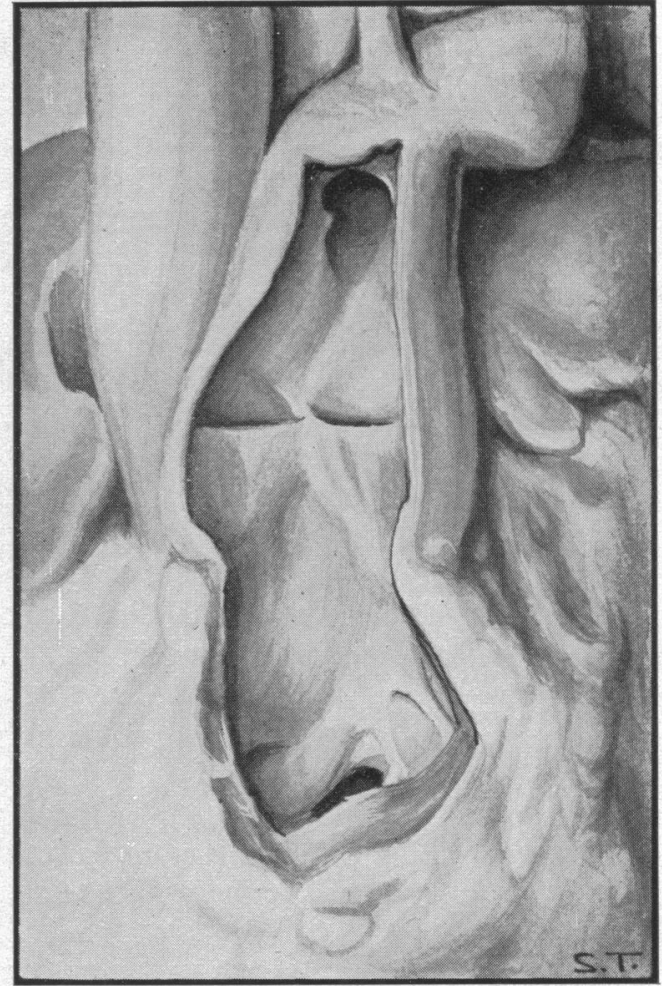

FIG. 2.-Drawing of a lower infundibular stenosis. The pulmonary valve is normal and there is a relatively large chamber below it. A fibrous infundibular stenosis is seen $24 \mathrm{~mm}$. below the valve. The subclavian-pulmonary anastomosis is seen at the top of the figure. In this patient the infundibular stenosis shown was the upper fibrous ring and there was another below it (see text). Case 24.

by which blood reached the pulmonary trunk obviously raises difficulties in the surgical technique of direct attack on the stenosis-an operation that was in fact attempted. The outflow tract started as a short infundibular canal bounded below and above by fibrous rings, the first being circular and $8 \mathrm{~mm}$. in diameter and the second oval and 8 by $5 \mathrm{~mm}$. Between these rings the canal expanded chiefly to the left to form a chamber $9 \mathrm{~mm}$. long, $18 \mathrm{~mm}$. wide, and $14 \mathrm{~mm}$. deep. After the second ring there was a second and larger infundibular chamber $24 \mathrm{~mm}$. long, $26 \mathrm{~mm}$. at its widest, and $12 \mathrm{~mm}$. deep. It also expanded to the left, further and more superficially than the lower chamber, with which it was connected at its left-most and down-most extremity by a third very small fibrous ring, $3 \mathrm{~mm}$. in diameter. It had also a diverticulum running for $10 \mathrm{~mm}$. to the right to end blindly in the muscle of the right ventricle in its upper part, in front of the root of the aorta and not far from the A-V groove. The second chamber finally ended at the pulmonary valve ring which was normal (Fig. 2).

In most of these hearts there seems to be a small contracted infundibulum with much hypertrophy of the muscle, and these changes must add to the difficulty that the blood already has in reaching the lungs because of the localized fibrous ring. Undoubtedly, specimens examined post mortem have contracted and may exaggerate this impression, and Mr. Brock with his experience of feeling the infundibulum during life thinks that this is most important. On the other hand, some angiocardiograms and particularly those taken at short intervals, where the state of affairs during systole 


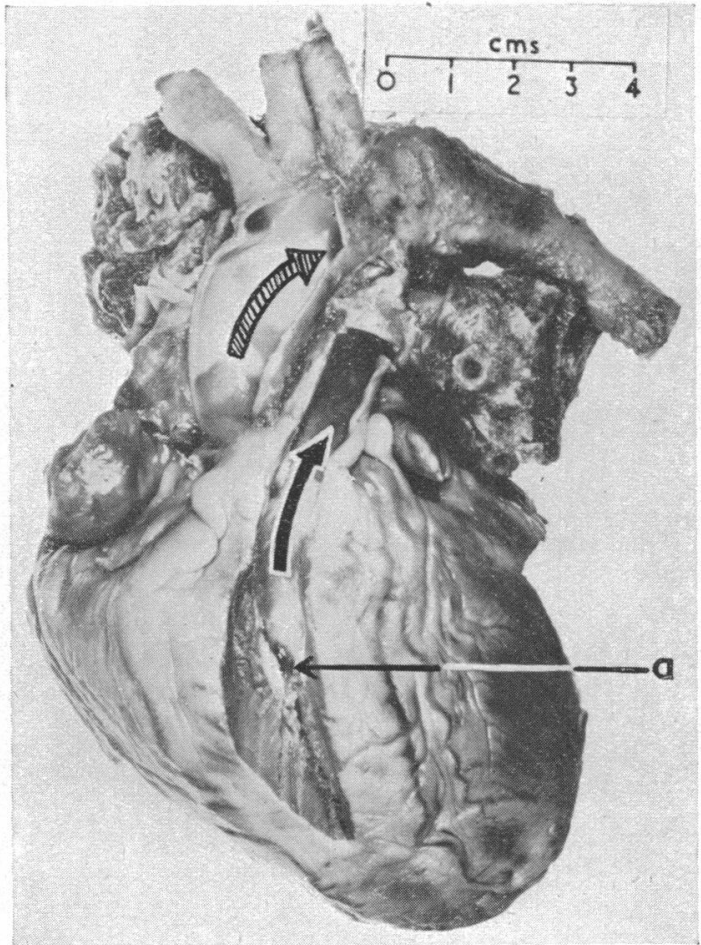

FIG. 3.-Photograph of a characteristic specimen of Fallot's tetralogy with a low infundibular stenosis $(a)$. The black arrow indicates the flow through this to the pulmonary trunk and the hatched arrow the aorta. No operation had been performed. Case 14 .

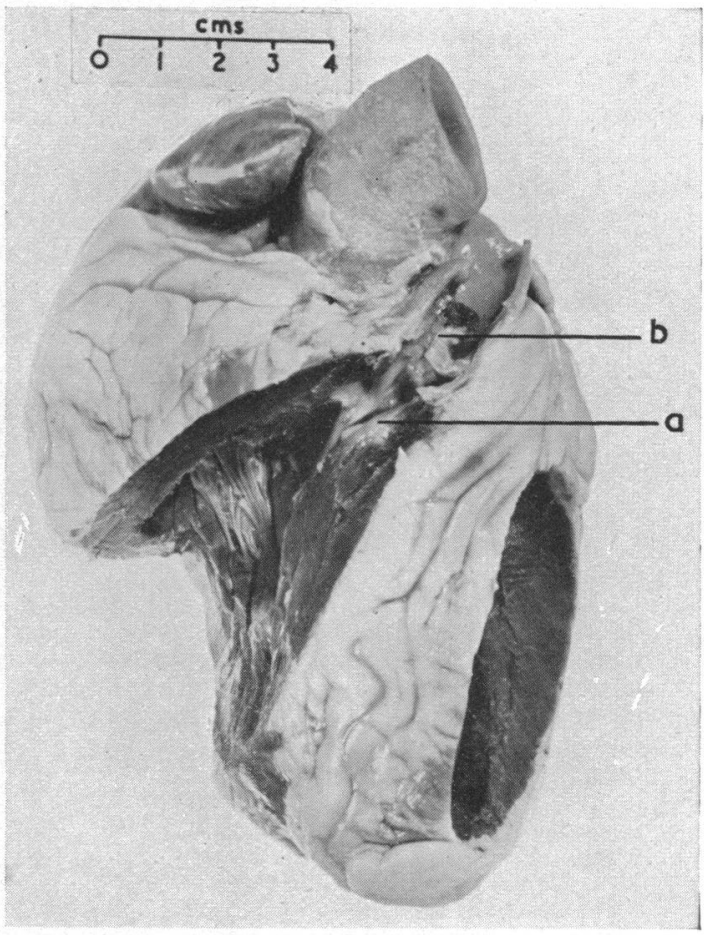

Fig. 4.-Photograph of the heart from a case of Fallot's tetralogy with infundibular stenosis $(a)$ and valvular stenosis (b). There was unusually severe fibrosis and calcification of the pulmonary valve in this patient who had lived to the age of 27 years. Case 10.

and diastole can be distinguished, do show much narrowing of the whole infundibular region; it has been suggested that there is some under-development and abnormality of the infundibulum even in the cases where the stenosis is valvular only.

Valvular Stenosis, alone or with Infundibular Stenosis. In only two hearts out of the 25 was the stenosis wholly valvular (Cases 11 and 21). In both the opening between the right ventricle and infundibulum was wide and high so that the infundibulum could not be described as either a canal or a chamber: it was a relatively normal outflow tract bound distally by the stenosed valve. The valve in each case presented the familiar appearance of a conical diaphragm, convex on its pulmonary artery surface, with a small central orifice. In both the pulmonary trunk was dilated for a short distance distal to the valve and was thereafter under-developed, having the calibre about half that of the aorta.

A combination of infundibular with valvular stenosis existed in 5 of the 25 hearts; there was no consistency in the position of the infundibular stenosis, which might be high or low or intermediate. A photograph of a specimen with stenosis at both sites from an older patient is shown in Fig. 4. Another example is shown in Fig. 5 (Case 22): the infundibular stenosis (shown in the lower window cut in the infundibulum) was low in position, so that a chamber $8 \mathrm{~mm}$. long existed between it and the stenosed pulmonary valve, which is sectioned longitudinally by the upper of the two windows. The valvular stenosis always had the same conical diaphragmatic form except that in Case 23 where it was not very severe it was eccentric, as it often is with congenital aortic stenosis (Campbell and Kauntze, 1953). 
Fig. 5.-Drawing of a heart from a case of Fallot's tetralogy with valvular and infundibular stenosis. The pulmonary trunk is small and hidden. The upper window in the outflow tract of the right ventricle shows a conical-shaped pulmonary valvular stenosis that has been sectioned longitudinally. The lower window shows the infundibular stenosis that was $8 \mathrm{~mm}$. below the valve. Case 22 .

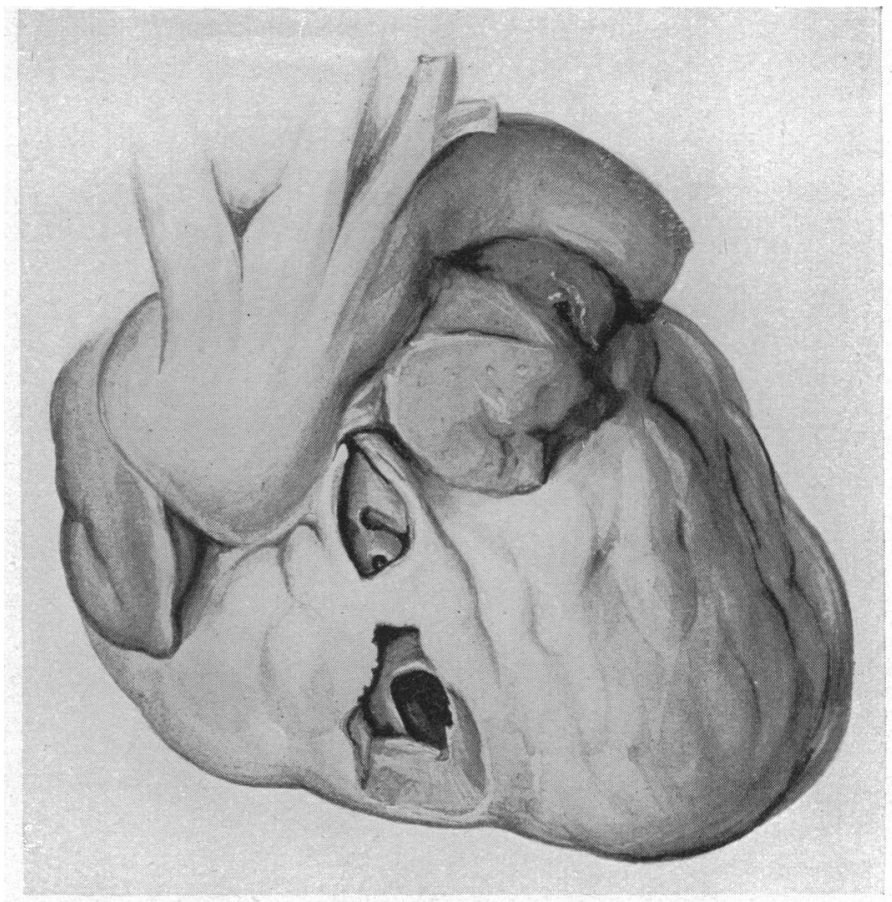

The pulmonary valve was often bicuspid. It was formed of two fused cusps only in both cases with lone valvular stenosis, and in two of the five where this was combined with infundibular stenosis: in the other three it was formed of three fused cusps. In the cases where the stenosis was infundibular only the pulmonary valve was formed of three cusps in eight cases and of two cusps in three. In Case 9 the aortic valve was also bicuspid.

Calcification of the pulmonary valve was unusual even when there was stenosis, but in Case 11, aged 24, the left cusp was distorted by thrombus and at the base by calcification which extended into the sinuses of Valsalva, and in Case 10, aged 27, the valve was extremely calcified and almost entirely occluded by recent thrombus.

Associated Abnormalities. Only two hearts presented abnormalities in addition to those of Fallot's tetralogy. In Case 17 a moderate degree of aortic valvular stenosis was present with complete fusion of the commissure between the anterior and left cusp and slight fusion of the other two commissures: the three cusps were normally developed, equal in size, and did not appear scarred or distorted, and the lesion was thought to be developmental. In Case 15, there was a slight constriction of the aorta that was thought to be without functional significance at the usual site of coarctation of the aorta.

Case 3 was an ordinary case of Fallot's tetralogy as far as the heart was concerned but the left pulmonary artery was completely occluded about $10 \mathrm{~mm}$. from its origin, where it was joined by the ligamentum arteriosum. In Case 7, who had a right-sided aortic arch, the ligamentum arteriosum was not on the right but passed from the left subclavian to the left pulmonary artery.

Case 6 was the only one in this series where the congenital abnormalities seemed to be due to the mother having rubella during the second month of her pregnancy. In addition to the cardiac findings there was some mental defect and a congenital cataract of the left eye. A report from the Bristol Eye Hospital six years before described a constant rotary nystagmus, the left globe rather smaller than the right, and a dense lens opacity in the anterior cortex of the left eye; the child had two needlings with some lens swelling into the anterior chamber. When admitted for her operation Mr. Law found a right fixation nystagmus; pale eye grounds with engorged veins, probably an 
albinoid basis; and opacity of the lens; the vitreous appeared clear and there was no microophthalmia.

Comment. Although the numbers are small it seems worth attempting to show some correlation between the different features of the tetralogy. There is a small but definite correlation between the severity of the pulmonary stenosis and of the right ventricular hypertrophy, and between the latter and the degree of dextroposition of the aorta. But the variations are unexpectedly wide and cannot be accounted for by such variants as the size of the ventricular septal defect, the position of the pulmonary stenosis, or the presence or absence of an atrial septal defect.

Site of the Stenosis in other cases. These and later necropsies in our patients during 1947-52 have included 10 with most features of Fallot's tetralogy but with pulmonary atresia and 48 with Fallot's tetralogy. Excluding the 10 with atresia, three-fifths of those with Fallot's tetralogy had infundibular stenosis only, one-fifth had infundibular and valvular stenosis, and rather more than one-fifth had valvular stenosis only.

In our earlier patients who had a subclavian-pulmonary anastomosis, the pericardium was not opened so the exact site of the stenosis is not known. Among our more recent patients operated on by Mr. Brock, Mr. Holmes Sellors, and Mr. Hill, there are 103 where the surgeon was reasonably satisfied about the site of the stenosis. Less than one-sixth of these had both infundibular and valvular stenosis, and about equal numbers of the remainder had valvular or infundibular stenosis.

In our 151 patients where the site of the stenosis was settled at necropsy or at operation, half had infundibular stenosis only, one-sixth infundibular and valvular, and one-third valvular stenosis only.

Donzelot et al. (1952) have described their surgical deductions from a study of 54 necropsies10 with pulmonary atresia and 44 with Fallot's tetralogy. In one of the former (their number 185) the atresia was unusual because it was due to occlusion of the valve and would have been amenable to surgery-a condition we have seen for the first time only recently (Case O332). In one other there was a combination of this with severe infundibular stenosis and surgery might have been possible, but the others agree with the view we have put forward that the nature of the obstruction makes direct surgery impossible at present in pulmonary atresia (Allenby et al., 1950). Of their 44 cases of Fallot's tetralogy there were only 4 with pure valvular stenosis, but 16 with valvular and infundibular stenosis. There were 24 with pure infundibular stenosis, one-fifth being high and one-fifth low and the remainder nearer the middle. Only a quarter of these showed an infundibular chamber of significant size. They distinguished 9 of the 44 cases as showing very little dextroposition of the aorta and 7 as showing this in an extreme form, the aorta in 3 of these coming almost entirely from the right ventricle as in our Case 5.

\section{The Clinical Picture in Fallot's Tetralogy}

Not much need be said about the clinical findings in these patients as they agree with those that have been given in other series. The patients were mostly between 7 and 20 years of age and were on the average (14 years) rather older than in most series, because they included a large proportion who died after operation and we have found the mortality increases with age after 20 years.

One point of interest is the relative fitness with subsequent deterioration of some of the older patients-a feature that is more common with pure pulmonary valvular stenosis. For example, Case 17, who was 29 when he died, was able to spend a long day in the field as a surveyor and was not greatly handicapped until three years before his death. He was suspected for this reason, of having a pure pulmonary stenosis though the relatively small heart favoured Fallot's tetralogy and this diagnosis was confirmed by angiocardiography. In his case the pulmonary valve showed unusual calcification but often increasing fibrosis follows the stresses and strains caused by the unusual anatomy and leads to more severe stenosis. Our general experience is that when a patient with pulmonary stenosis starts deteriorating, the end is not far away unless something can be done. Case 11, aged 24, became worse in the same way, but here the cause was thrombus on the valve, and it seemed that the passage must have become much smaller as the result of this in the last year or so. 
All the patients had some degree of polycythæmia and the hæmoglobin percentages were between 110 and 180 and averaged 143 per cent. Eighteen of the 25 patients had squatted, most of them a great deal.

The Shape of the Heart. It is difficult to pick out any cardiac outline that will be found in all cases of Fallot's tetralogy. The most characteristic sabot-shaped heart is often seen in small children, but was present in few of these patients. We have selected four type teleradiograms, and most of the remainder resemble one or other of these fairly closely. In the first there is distinct hollowing of the pulmonary arc as when the heart is sabot-shaped, though it is minimized when it is small and central (Fig. 6). In the second this hollow has been filled in and the upper border is almost straight (Fig. 7). In the third the infundibular chamber causes some prominence of part of the left border (Fig. 8), and it may sometimes be much more than this. In the fourth there is more rounding of the lower left border from hypertrophy of the right ventricle (Fig. 9). The heart from Case 5, where the aorta arose entirely from the right ventricle, and the largest heart are shown in Fig. 10. When there is a valvular stenosis the pulmonary trunk and left pulmonary artery tend to be more prominent though not as much as with pulmonary valvular stenosis with a closed ventricular septum.

Case 6 was exceptional in showing a much larger heart than is usual in Fallot's tetralogy (Fig. 10B). It was sabot-shaped with a very deep, sharp pulmonary bay and a broad aorta - the picture that is characteristic of pulmonary atresia or truncus arteriosus-and in relation to the aorta the pulmonary trunk was much the smallest of the series. We thought the large atrial septal defect might explain this unusual picture, but cases with a single atrium do not generally show great cardiac enlargement and it does not seem possible that there was a large left-to-right shunt.

With this exception, the cardiothoracic ratio was never above 54 per cent and in nearly half it

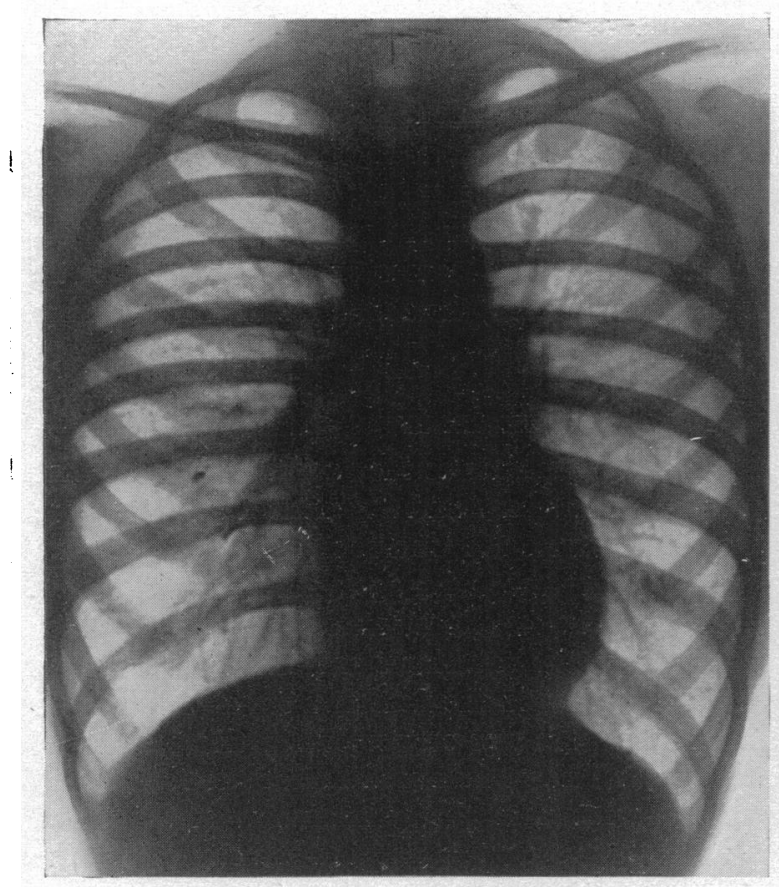

FIG. 6.-A characteristic heart in Fallot's tetralogy. The heart is rather small and central with a blunt apex and a hollow pulmonary bay. From a girl, aged 14, with a cardiothoracic ratio of 46 (11.0/24 cm.). Case 14 .

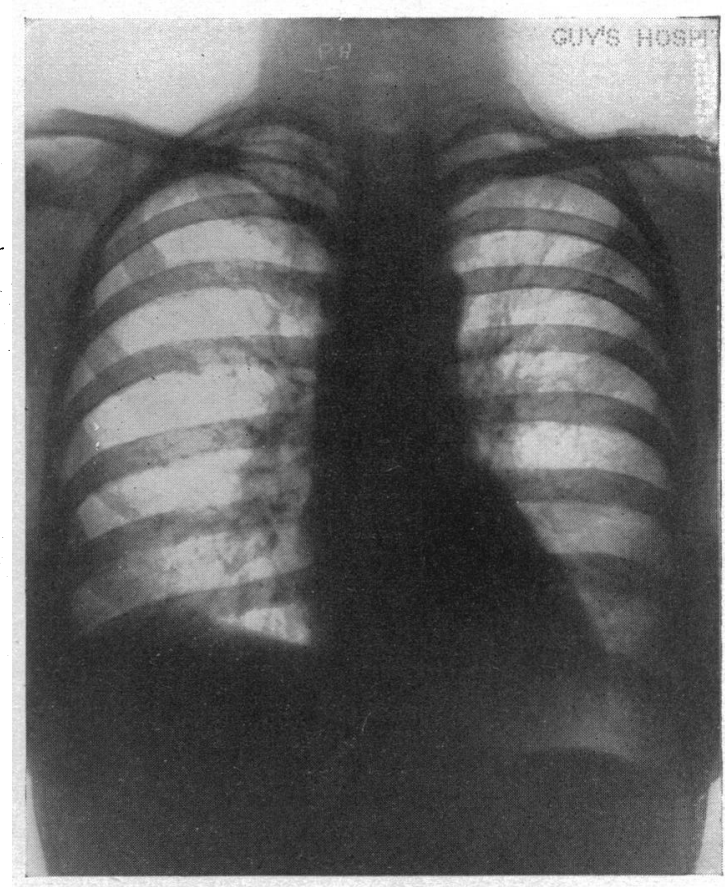

FIG. 7.-A characteristic heart in Fallot's tetralogy with a straighter left border. From a woman, aged 36, with a cardiothoracic ratio of 50 $(11 \cdot 7 / 23 \cdot 5 \mathrm{~cm}$.). Case 15 . 


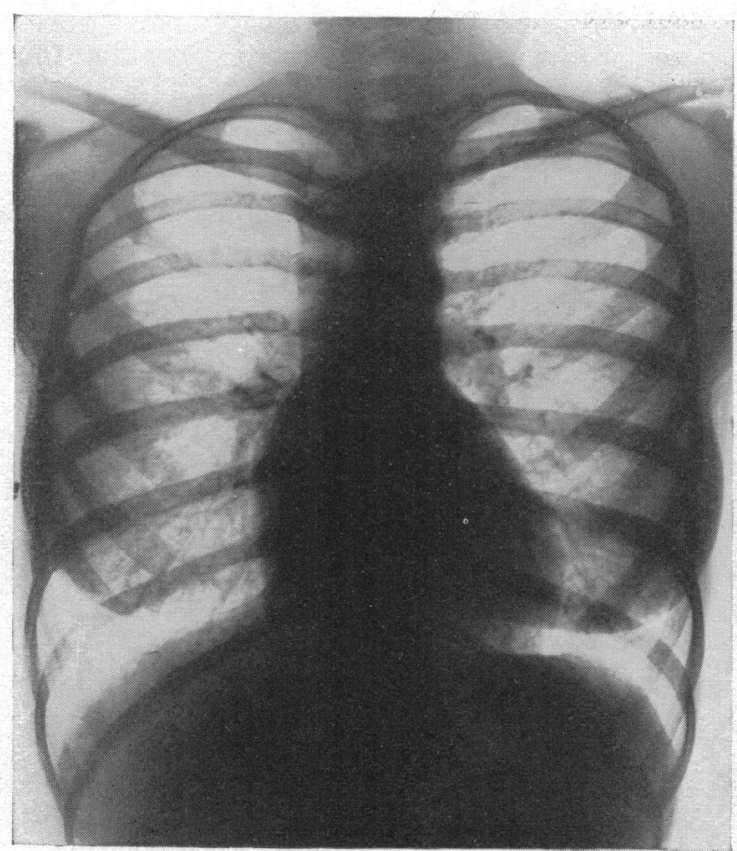

Fig. 8.-A characteristic heart in Fallot's tetralogy with slight prominence of the upper left border due to an infundibular chamber. From a woman, aged 20, with a cardiothoracic ratio of $49(12 \cdot 0 / 24 \cdot 5 \mathrm{~cm}$.). Case 19.
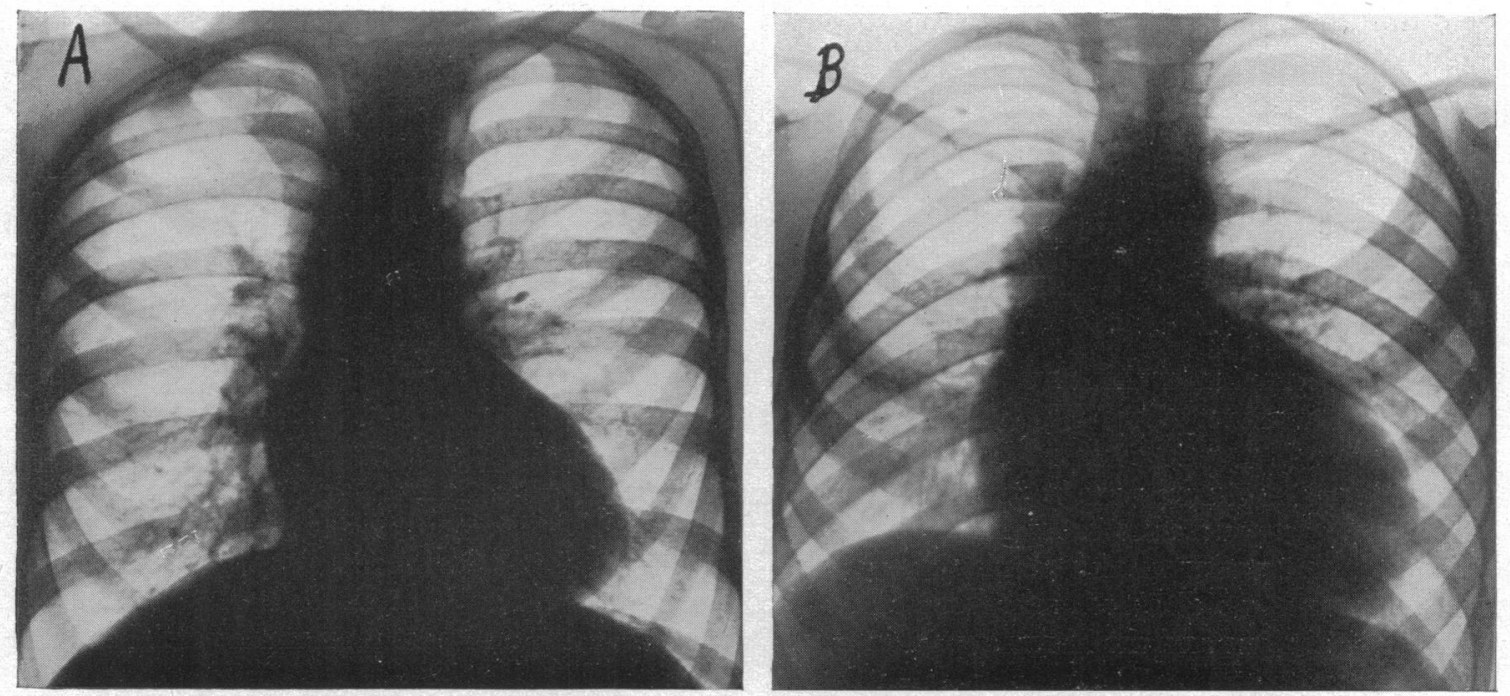

Fig. 10.-Teleradiograms from two less usual cases. (A) With the aorta arising entirely from the right ventricle, c.t.r. $53(11 \cdot 0 / 20 \cdot 8 \mathrm{~cm}$.), Case 5. (B) The largest heart with the picture that is seen more often with pulmonary atresia, from a patient who had Fallot's tetralogy with a very small pulmonary trunk and a large atrial septal defect, c.t.r. $63(11 \cdot 3 / 17 \cdot 6 \mathrm{~cm}$.). Case 6 .

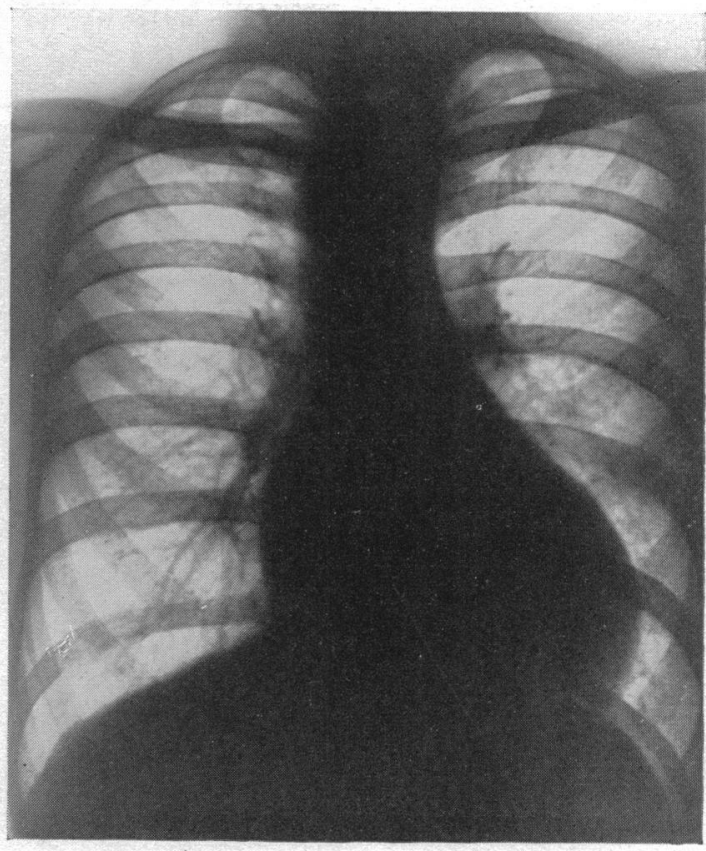

FIG. 9.-A characteristic heart in Fallot's tetralogy rather larger than the others; in uncomplicated cases the heart is not often larger than this. The aortic arch is right-sided. From a man, aged 29 , with a cardiothoracic ratio of 52 $(13 \cdot 2 / 25 \cdot 5 \mathrm{~cm}$.). Case 17 . 
was between 45 and 49 per cent. We think that a cardiothoracic ratio above 54 should raise the question whether there is some other abnormality present. Brown (1950) has emphasized that the heart is generally normal in size or only slightly enlarged.

The aortic arch was right-sided in six of these cases, very close to the proportion of one-quarter that has been found so often.

Right ventricular enlargement is generally obvious on radioscopy, but rotation of the heart may simulate enlargement of the left ventricle as well in cases where it is not enlarged.

The Electrocardiogram. Right ventricular preponderance in the electrocardiogram is more constant and more reliable. All agree on its frequency in those diagnosed as Fallot's tetralogy, but a few such cases fail to show it. The present series does not help as regards these few exceptions, for there were none. We have not got chest leads in the earlier cases, but all where we have showed right ventricular preponderance. We have found that gross right axis deviation (small or more often insignificant RI and SIII and large RIII and SI) is almost the best evidence of right ventricular preponderance (Woods, 1952). With the single exception of Case 9, who had partial bundle branch block and almost a bilocular heart, all had gross right axis deviation as defined above, SI averaging $12 \mathrm{~mm}$. and RIII averaging $13 \mathrm{~mm}$.

\section{Cases Other than Fallot's Tetralogy}

A condition other than Fallot's tetralogy or pulmonary atresia was found in 24 of the 55 cases of congenital heart disease (see Table II). Seven of them were infants and had come to the postmortem room with a clinical diagnosis merely of congenital heart disease, but the other 17 had been investigated more or less completely before death. Some of them have formed the subject of papers already published in Guy's Hospital Reports and to these no further reference will be made here. The two cases of Ebstein's anomaly of the tricuspid valve have been reported by Baker et al. (1950).

Six cases of congenital pulmonary stenosis with closed ventricular septum were reported in detail by Allanby and Campbell (1949), and there is one other to add. This patient (Case 40 of the present series), was a girl of 10 years who died shortly after pulmonary valvotomy. The heart weighed $370 \mathrm{~g}$. (normal for age $120 \mathrm{~g}$.) and there was the usual very great hypertrophy of the muscle of the right ventricle, its thickness being $9 \mathrm{~mm}$. against $10 \mathrm{~mm}$. for the left ventricle. Apart from this the right ventricle was normal up to the valve, which consisted of a diaphragm, convex upwards, formed from two cusps only. The valve-ring was normal in size $(14 \times 14 \mathrm{~mm}$.), and the central opening had been dilated at operation so that it was not possible to estimate its natural dimensions. Above the stenosed valve the pulmonary trunk was dilated, having a diameter of $20 \mathrm{~mm}$. as against $14 \mathrm{~mm}$. for the aorta. There was a large atrial septal defect in the posterior and upper part of the septum.

\section{Atrial Septal Defect}

The six samples of this are described in two groups. The first, Cases $41-44$, consists of four adults-all women. Two had mitral stenosis also and had been diagnosed as Lutembacher's syndrome, which was confirmed post mortem. Each had been in and out of congestive heart failure for more than a year before her death from this cause. The third (Case 43) lived to the age of 63 and, though a little breathless since school days, was hardly troubled by it until she was 49, when she had paroxysmal auricular fibrillation: when she was 54 fibrillation became established and she was more disabled, and from 60 to 63 she was often in hospital with congestive failure. The physical signs and the X-ray appearances were characteristic, and post mortem the atrial septal defect measured 50 by $35 \mathrm{~mm}$.

Case 44. F., 32. The fourth remained well until her first pregnancy at the age of 31 , when moderate dyspnœa and cyanosis in cold weather were first noticed. She developed odema of the ankles, and in hospital was found to be cyanosed and polycythæmic (Hb., $17.2 \mathrm{~g}$., red cells, 5.9 million) with some clubbing of the fingers. The heart was only moderately enlarged. There was palpable pulsation in the pulmonary area 
TABLE II

Cases of Congenital Heart Disease with Necropsy

\begin{tabular}{|c|c|c|c|c|c|c|}
\hline Case No. & \multicolumn{4}{|c|}{ Diagnosis } & $\begin{array}{c}\text { Sex and } \\
\text { age }\end{array}$ & Remarks \\
\hline $\begin{array}{l}\text { 1-25. } \\
26-31 . \\
32-33 . \\
34-40 . \\
\text { 40. (O041) } \\
\text { 41. (C201) } \\
\text { 42. (C223) } \\
\text { 43. (H312) } \\
\text { 44. (C229) } \\
\text { 45. (OA21) } \\
\text { 46. (C215) } \\
\text { 47. (OA18) } \\
\text { 48. (OA22) } \\
\text { 49. (P083) } \\
\text { 50. (P088) }\end{array}$ & $\begin{array}{r}\text { Fallo } \\
\text { Pulm } \\
\text { Ebste } \\
\text { Pulm } \\
\text { ven } \\
\text { P.V.S } \\
\text { Atrial } \\
, " \\
, " \\
, " \\
\text { Tricu } \\
\text { Atres } \\
\text { Single } \\
\text { Trans } \\
\text { tru }\end{array}$ & 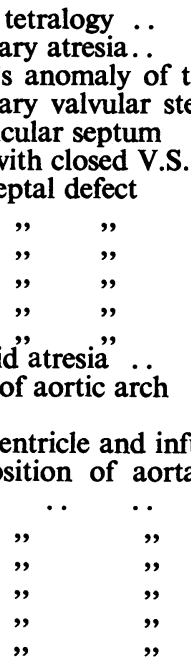 & $\begin{array}{l}. \\
.\end{array}$ & 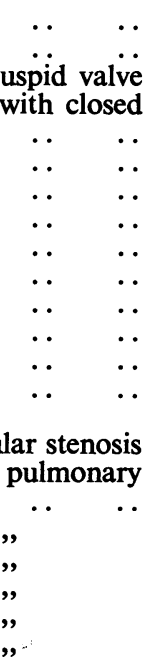 & \begin{tabular}{l} 
二 \\
\multicolumn{1}{c}{-} \\
F10 \\
F39 \\
F48 \\
F63 \\
F32 \\
M7mo. \\
F2mo. \\
F2wk. \\
F6wk. \\
F8 \\
F25 \\
F7 \\
M3 \\
F8mo. \\
M3wk. \\
M3mo.
\end{tabular} & $\begin{array}{l}\text { See Table I } \\
\text { Reported fully by Allanby et al., } 1950 \\
\text { Reported by Baker et al., } 1950 \\
\text { Cases } 34-39 \text { reported by Allanby and Camp- } \\
\text { bell, } 1949 \\
\text { With A.S.D. } \\
\text { With mitral stenosis } \\
\text { With mitral stenosis } \\
\text { Without mitral stenosis } \\
\text { Without mitral stenosis } \\
\text { Anomalous great veins } \\
\text { Large P.D.A. } \\
\text { No other abnormality } \\
\text { With V.S.D. and bicuspid aortic and pul- } \\
\text { monary valves } \\
\text { Transposition of aorta and P.T. also } \\
\text { Infundibular stenosis } \\
\text { Pulmonary stenosis } \\
\text { Transposed abdominal viscera, P.S. } \\
\text { Isolated dextrocardia } \\
\text { A.S.D. and P.D.A.: No V.S.D. } \\
\text { A.S.D. and P.D.A.: No V.S.D. }\end{array}$ \\
\hline
\end{tabular}

and a systolic murmur, but no thrill was felt; the pulmonary second sound was accentuated. In spite of rest in bed the odema persisted and after a month, as she was found to have albuminuria, Cæsarian section was performed; all went well for seven days, when she suddenly became gravely dyspnœic and died within half an hour. Post mortem, the cause of death was pulmonary embolism: the shape of the clot suggested that it had originated in the right atrium, and no thrombosis was found in the veins of the legs. The heart weighed $400 \mathrm{~g}$. and there was great hypertrophy of the right ventricle. A defect in the atrial septum measuring $20 \times 20 \mathrm{~mm}$. was the only other abnormality.

The first three patients were acyanotic and only developed some peripheral cyanosis terminally with their heart failure. The fourth said she was cyanosed only in cold weather and only recently; but the polycythæmia and clubbing were unusual and suggested that there might have been an added right to left shunt or enough changes in the lungs to interfere with oxygenation. Unfortunately she was not studied by catheterization and the necropsy did not suggest there had been thrombosis in the lungs before her terminal illness.

The second group consists of two infants who died suddenly and apparently as a result of this defect, before any precise diagnosis had been made. It is of interest to enquire why this defect, which is usually without symptoms for many years, should sometimes lead to death in infancy. There must have been an unusually large left-to-right shunt through the large defect, though this is not necessarily so even when there is a single atrium.

Case 45. M., 7 months. The heart weighed $150 \mathrm{~g}$. (normal for age $25 \mathrm{~g}$.); this great increase was caused by the hypertrophy of the right ventricle, the thickness of which was $12 \mathrm{~mm}$. compared with $4 \mathrm{~mm}$. for the left. There was no ventricular septal defect and the infundibulum of the right ventricle was normal except that it was greatly dilated, as was the pulmonary trunk with a calibre of $14 \mathrm{~mm}$. compared with $9 \mathrm{~mm}$. for the aorta. The ductus arteriosus was large but had closed normally. The right atrium was dilated and was about six times the size of the left atrium. It received blood from a normal right superior vena cava and also from a left superior vena cava which entered it from the left side, through a coronary sinus that was so large that it looked like a triangular posterior extension of the right atrium pointing to the left. The left atrium was thus a small ill-developed structure wholly at the back of the heart; it received the four pulmonary veins normally. The small atrial septum lay in the lateral plane at the back of the heart and was also the site of a large defect measuring $17 \times 10 \mathrm{~mm}$. 
Case 46. F. 2 months. The heart was very large and this was due to right ventricular hypertrophy. The pulmonary trunk was also very large. The atrial septum was normally placed but contained a large defect, $12 \mathrm{~mm}$. in diameter. In addition, the ductus arteriosus was widely patent.

\section{Miscellaneous Cases}

There was one example of tricuspid atresia and one example of atresia of the aortic arch: both these died in infancy. This last condition, as pointed out by Taussig (1947), is closely related to the infantile type of coarctation of the aorta. The third case had a single ventricle and infundibular stenosis and an unusually primitive type of heart.

Case 47. F., 2 weeks. Tricuspid Atresia. This infant died on the twelfth day after birth. The enlargement of the heart was mainly due to the large left ventricle. The right atrium was almost isolated, its only exit being into the left atrium through a small patency of the foramen ovale: there was no tricuspid valve. The left atrium received the pulmonary veins normally and the mitral valve was normal. The left ventricle was the only functional ventricle; both aorta and pulmonary trunk arose from it with a normal relationship and without any stenosis or abnormality of either of their valves. There was a rudimentary right ventricle lying behind a small ridge on the right lateral wall of this single ventricle. The ductus arteriosus was open, but appeared from the wrinkled state of its intima, to be in the process of closing. There was an appreciable local narrowing of the aorta at a point just above the ductus.

Case 48. F., 6 weeks. Atresia of the Aortic Arch. This was an infant who had had attacks of cyanosis since birth, in one of which it died. When not in an attack there was only slight cyanosis of the face; and a greater degree of cyanosis in the lower part of the body had not been noted. The heart was enlarged and there was a loud systolic murmur over the whole præcordium.

Post mortem, the heart weighed $70 \mathrm{~g}$. (normal for age, 20-25 g.) and many developmental anomalies were found. There was hypertrophy of both ventricular walls, the right measuring $7 \mathrm{~mm}$. in thickness and the left $8 \mathrm{~mm}$. A high ventricular septal defect of the Fallot type, measuring $10 \mathrm{~mm}$., was straddled by a large pulmonary trunk $(12 \mathrm{~mm}$. in diameter) and by a hypoplastic aorta $(6 \mathrm{~mm}$. in diameter), the roots of these two vessels, bearing a normal relation to each other. The valves of both were bicuspid. Both atria were normal, and there was only a slit-patency of the foramen ovale. The hypoplastic aorta branched once only, to form the right innominate and left common carotid arteries. The pulmonary trunk, after giving off its main right and left branches, continued as a slender ductus arteriosus of only $2 \mathrm{~mm}$. diameter and expanded distally to form the aortic arch $(4 \mathrm{~mm}$.) which gave off the left subclavian and left internal mammary arteries, and the descending aorta $(5.5 \mathrm{~mm}$.).

Both the aortic and pulmonary rings could be seen from the left ventricle, but the pulmonary was so much the larger of the two as to make it clear that in life blood flowed from the left ventricle through the septal defect into it. Thus the pulmonary trunk received blood from both sides of the heart and supplied the left arm and the lower part of the body though its only outlet besides the pulmonary capillaries was through the attenuated ductus.

Case 49. Single Ventricle with Infundibular Stenosis. This girl, aged 10 when she died, had been fully reported (Case 1, Campbell et al., 1953). She had a single ventricle, infundibular stenosis, and transposition of the aorta and pulmonary trunk. The single ventricle makes the transposition of little clinical importance so she is grouped separately.

\section{Transposition of the Aorta and Pulmonary Trunk}

The remaining six are examples of transposition of the great vessels, and though they had this in common they differed in other ways and showed other abnormalities. The first three (and Case 49) had pulmonary stenosis and this modifies the general picture and in some ways makes it more like that of Fallot's tetralogy. A subclavian-pulmonary anastomosis was performed with temporary success in Case 49 and was attempted in Case 50, and was being considered in the other two when they died.

The other three had transposition without pulmonary stenosis: two of them had no ventricular septal defect and maintained their circulation through a small defect of the atrial septum and a patent ductus arteriosus - conditions that often lead to death in early infancy (Astley and Parsons, 1952) as in these cases.

There were other complex defects in some of the patients. Case 52 had transposition of the abdominal viscera and Case 53 had isolated dextrocardia. We have found, in examining hearts 
of this sort, that the external appearance of the atria offers the best basis for judging the abnormal arrangement of the rest of the heart. There is generally one atrium that is larger and lies anteriorly and receives blood from the great veins of the body, and its companion is smaller, lies posteriorly, and receives blood from the lungs. These, of course, are normally the right and left atria respectively, but when there is transposition of the abdominal viscera they are often reversed. The sinus venosus appears to be the most stable part of the developing primitive cardiac tube, and the more anterior ventricular and bulbar portions seem more liable at first to abnormal torsion and later to defective absorption.

These cases of transposition also differed in the relationship of the aorta and pulmonary trunk. In Cases 49 and 50 the aorta was well to the right of and somewhat anterior to the pulmonary trunk. In Cases 51 and 52 it was almost directly in front of the pulmonary trunk and was hardly moved to the right. In Cases 54 and 55, and in Case 53 (allowing for the dextrocardia), the position was intermediate and the pulmonary trunk was also much nearer its normal size: these were the patients who had no pulmonary stenosis.

Case 50. M.S., aged 25 when she died, was unusual in having, in addition, both gout and thrombocytopenic purpura. She has been reported by Campbell and Suzman (1951), so only essentials of the anatomy are given here. At necropsy the heart was enlarged $(400 \mathrm{~g}$.) and the right ventricle was hypertrophied. There was a large defect of the upper part of the ventricular septum, $30 \mathrm{~mm}$. in diameter. The pulmonary trunk over-rode this, slightly to the left of the aortic orifice. There was a low infundibular stenosis and bicuspid pulmonary valves. The pulmonary trunk was $10 \mathrm{~mm}$. in diameter against $24 \mathrm{~mm}$. for the aorta, which arose entirely from the right ventricle.

Case 51. C.L., a girl of 7, is being reported separately by Dixon, so only a summary will be given here. Partial transposition of the aorta and small pulmonary trunk both arising from the right ventricle. Pulmonary infundibular stenosis. Right (and left) atrial appendages to left of aorta. Atrial septal defect, 27 by $12 \mathrm{~mm}$., (persistent ostium primum). Ventricular septal defect, $18 \mathrm{~mm}$. in diameter, as in Fallot's tetralogy, but several smaller slits also. Common pulmonary vein.

Case 52. D.P., a boy of 3 years, is also to be reported separately by Brinton so is only summarized. Situs inversus with lævocardia. Anatomical transposition of the aorta and pulmonary trunk but both arising from the right ventricle, the only exit from the left ventricle being through the ventricular septal defect. Pulmonary infundibular and valvular stenosis.

Case 53. Isolated dextrocardia. Transposition of great vessels. Triloculate heart with single atrium and common $\mathrm{A}-\mathrm{V}$ valve. The veins and atria normally related but the ventricles transposed.

M.D. was cyanosed and œdematous at birth, but only for 36 hours. She was admitted to Guy's Hospital under Dr. Evans at 4 months, when she weighed $8 \frac{1}{2}$ pounds. She was not cyanosed, but the hæmoglobin was only 68 per cent. The apex beat was in the mid-axillary line in the fifth right intercostal space, and there was an apical systolic murmur. The chest film and electrocardiogram confirmed the dextrocardia, but the liver and stomach were normal in position. She died at 8 months outside London and the heart was partly dissected and sent to us.

The external surface of the atria was normal, the right side being large and anterior and the smaller left side posterior. The atrial appendages were normal. The great veins were normal and entered the right side of the heart normally, as did the four pulmonary veins posteriorly. But within, there was a common atrial cavity. the septum being absent except in its uppermost part. The free border of this lay over a common A-V valve which possessed four cusps.

The right ventricle had the external appearance of a mirror-image left ventricle and was capacious and muscular $(7 \mathrm{~mm}$. thick) whereas the left, looking like a mirror-image right ventricle was smaller $(5 \mathrm{~mm}$. thick). The ventricular septum lay in an antero-posterior plane and was better developed than the atrial septum, but was deficient above and a cusp of the common A-V valve was attached to its free upper border.

The relationship of the great vessels was the opposite of normal, the pulmonary ring lying posteriorly and to the right and the aortic ring anteriorly and to the left. Neither of these was constricted below or at the valves, which were both tricuspid and normal. The diameter of the pulmonary trunk was $9 \mathrm{~mm}$. and that of the aorta $8 \mathrm{~mm}$. The aorta formed a right-sided arch and gave off left innominate and right carotid and subclavian arteries. The ligamentum arteriosum passed from the arch to the right pulmonary artery.

The coronary arteries reinforced the picture, the anterior being a mirror-image of the left, and the posterior a mirror-image of the right. The anterior arose from the centre of the right anterior aortic sinus and ran to the right for $6 \mathrm{~mm}$., dividing into a descending branch which ran down the interventricular groove and a circumflex branch which continued to the right in the A-V groove. The posterior artery arose from the posterior aortic sinus close to its left commissure and ran to the left and posteriorly: after $23 \mathrm{~mm}$. it divided into a descending branch which ran down in the interventricular groove posteriorly, and a circumflex branch which continued round in the A-V groove. 
Case 54. Transposition of the great vessels. The greater and lesser circulations separate except through a trivial A.S.D. and a large P.D.A. No V.S.D.

M.P. was born in Guy's Hospital: he was not cyanosed at birth but severe cyanosis developed on feeding and continued till his death from congestive heart failure on the twenty-third day. A harsh systolic murmur was heard over the præcordium.

The external appearance of the heart was normal, except for the dilatation of the right ventricle. The great veins, the pulmonary veins, and both atria were normal. The atrial septum was normal except for a small ostium secundum, measuring $1 \times 2 \mathrm{~mm}$. The right ventricle was hypertrophied and dilated $(4 \mathrm{~mm}$. thick) and its outflow tract joined the aorta, whose ring lay anteriorly and to the right. The left ventricle was smaller ( $2 \mathrm{~mm}$. thick), and its outflow tract, which showed an infundibular stenosis of moderate degree, led to the pulmonary ring which lay posteriorly and to the left. The A-V valves were normal and the ventricular septum contained no defect. The aortic arch was left-sided and there was a widely patent ductus arteriosus $(3 \mathrm{~mm}$.) between the aorta and the left pulmonary artery. The diameters of the aorta and the pulmonary trunk were $4 \mathrm{~mm}$. and $3 \mathrm{~mm}$. respectively.

Case 55. Transposition of the great vessels. The greater and lesser circulations separate except through a trivial A.S.D. and a P.D.A. of nermal dimensions. No V.S.D.

T.McD. was admitted to Guy's Hospital for dyspnœa and cyanosis on exertion. A systolic murmur was audible all over the præcordium. The chest film confirmed the enlarged heart and pleonæmic lungs. The liver was enlarged and there were crepitations at both lung-bases. The cardiogram showed right ventricular preponderance and a large and pointed PII. The pyrexia continued and he died when three months old, from intracranial hæmorrhage complicating pyelonephritis.

The heart was greatly enlarged, especially the right atrium and ventricle. The right atrium received the great veins normally, the septum showed a slit-patency only, and the tricuspid valve was normal. The right ventricle was hypertrophied and dilated and the outflow tract led to the aortic ring which was situated to the right and posteriorly. There was no defect of the ventricular septum. The left atrium received the pulmonary veins normally and the mitral valve was normal. The left ventricle gave origin to the pulmonary trunk though it was more normally situated to the left and anteriorly. The ductus arteriosus was patent but not large, and the branches of the aorta, including the coronary arteries, were normal.

\section{SUMMARY}

There were 55 necropsies at Guy's Hospital in 1947-50 on patients with congenital heart disease. Twenty-five of these were examples of simple Fallot's tetralogy and have been described fully. The general picture is very similar in each case though there is a good deal of variation in detail.

A functional defect of the atrial septum, about 9 by $5 \mathrm{~mm}$., is present in more than one-third, but does not seem to make any difference to the clinical picture. The ventricular septal defect is nearly always just below the valves and is bounded below by a saddle-shaped ridge of muscle clothed with smooth endocardium: its size corresponds with the size of the heart and is commonly between 10 and $16 \mathrm{~mm}$. in transverse diameter.

The aorta always over-rides this except in the rarer cases where it arises entirely from the right ventricle, and the degree to which this happens varies between one-quarter and seven-eighths, and averages three-fifths, i.e. more over the right than over the left ventricle. The right ventricle is always hypertrophied and is commonly 50 per cent thicker than the left, averaging nearly $12 \mathrm{~mm}$. against $8 \mathrm{~mm}$. for the left.

The pulmonary trunk is smaller than the aorta, generally between 40 and 80 per cent of its size, instead of being about the same; the average diameters were $10 \mathrm{~mm}$. and $17 \mathrm{~mm}$. Taking our figures from a more extensive series the stenosis is infundibular alone in one-half, infundibular and valvular in one-sixth, and valvular alone in one-third. When it is infundibular, the site is commonly from 5 to $25 \mathrm{~mm}$. below the valve and is sometimes multiple: there is generally a fibrous ring, but the whole tract is narrow and under-developed. When it is valvular it has the familiar appearance of a conical diaphragm with a small central orifice, and has developed from two cusps or from three cusps in about equal numbers of cases.

The clinical picture of these patients with Fallot's tetralogy has been referred to shortly, and the commoner X-ray appearances have been described. The classical sabot-shaped heart is not very common except in infants and there is much variation in the shape and appearance of the heart, but most resemble one of four types illustrated. Right ventricular enlargement is generally obvious 
on radioscopy, but rotation of the heart may simulate enlargement of the left ventricle as well. Right ventricular preponderance in the electrocardiogram is more constant and more reliable.

Six other patients had the general features of Fallot's tetralogy but with pulmonary atresia instead of stenosis. Seven had pulmonary valvular stenosis with a closed ventricular septum: all but one of these had a right-to-left shunt through the atrial septum. Two had Ebstein's anomaly of the tricuspid valve. These three groups have been described elsewhere.

Six others had an atrial septal defect. Three of these, two of whom had mitral stenosis also, lived to middle age and the fourth with a very large defect was hardly inconvenienced till she was 49 and lived to 63 years of age. The other two with very large defects and great right ventricular hypertrophy died in infancy.

There were single examples of tricuspid atresia and of atresia of the aortic arch: both these died in infancy. One patient had an unusually primitive type of heart with a single ventricle, infundibular stenosis, and transposition of the aorta and pulmonary trunk. Six others had transposition, three with and three without pulmonary stenosis. Most of them died in infancy, but one with pulmonary stenosis lived 25 years. One had in addition isolated dextrocardia and another had transposed abdominal viscera.

We should like to thank those who have worked with us on the patients with congenital heart disease, especially the late Dr. G. D. Channell. His knowledge of anatomy and embryology made him an ideal colleague for this work and the measurements of the earlier cases were mostly his. His death in an explosion at the Brompton Hospital while he was working on one of these specimens was a tragic loss.

\section{REFERENCES}

Allanby, K. D., Brinton, W. D., Campbell, M., and Gardner, F. (1950). Guy's Hosp. Rep., 99, 110.

, and Campbell, M. (1949). Guy's Hosp. Rep., 98, 18.

Astley, R., and Parsons, C. G. (1952). Brit. Heart J., 14, 13.

Baker, C. G., Brinton, W. D., and Channell, G. D. (1950). Guy's Hosp. Rep., 99, 247.

Brown, J. W. (1950). Congenital Heart Disease. 2nd ed., Staples Press, London.

Campbeli, M., and Kauntze, R. (1953). Brit. Heart J., 15, 179.

$\longrightarrow$, Reynolds, G. R., and Trounce, J. R. (1953). Guy's Hosp. Rep., 102, 99.

二, and Suzman, S. (1951). Circulation, 4, 329.

Donzelot, E., d'Allaines, F., Dubost, Ch., Métianu, C., Durand, M., and Dubost, C. (1942). Sem. Hôp., Paris, 28, 877 .

Taussig, H. B. (1947). Congenital Malformations of the Heart. New York, The Commonwealth Fund, p. 486.

Woods, A. (1952). Brit. Heart J., 14, 193. 